\title{
A long-term, strategic approach to evidence generation and knowledge translation in NSW, Australia
}

\author{
Sarah Thackway a,b, Danielle Camplella and Tina Loppachera \\ a NSW Ministry of Health, Sydney, Australia \\ b Corresponding author: sthac@doh.health.nsw.gov.au
}

\section{Article history}

Publication date: February 2017

Citation: Thackway S, Campbell D, Loppacher T. A long-term, strategic approach to evidence generation and knowledge translation in NSW, Australia. Public Health Res Pract. 2017;27(1):e2711702. doi: http://dx.doi. org/10.17061/phrp2711702

\section{Key points}

- Research funders are in a unique position to influence activities that support implementation of research findings to improve health

- NSW Health has built an integrated population and health services research portfolio including different types of investment and policy focuses and with an explicit focus on translation

- This strategic investment was recently enhanced with the establishment of the Translational Research Grants Scheme to support practitioner-led research that is directly translatable into local practice

\section{Abstract}

There is a growing body of literature about the barriers to, and enablers of, the use of research evidence in policy and practice. Research funders are in a unique position to influence activities aimed at promoting research use. During the past decade, NSW (New South Wales) Health has systematically built and invested in an integrated population and health services research portfolio made up of different types of investment and policy focuses. Each of these investments has an explicit focus on translation.

Ensuring a long-term, sustained, strategic approach to priority-driven research generation, true coproduction of evidence and effective knowledge translation will continue to deliver results for NSW. The NSW Population Health Research Strategy 2017-2021, currently in development, will have a strong emphasis on fostering environments and actions that promote the use of research in policy and practice.

\section{Introduction}

There is a growing body of literature about the barriers to, and enablers of, the use of research evidence in policy and practice. ${ }^{1,2}$ Research funders are in a unique position to influence activities aimed at promoting research use. Health research funding agencies worldwide are increasingly recognising their role in knowledge translation and have developed strategies to support this role, ranging from agency-wide services and funding mechanisms to specific communication requirements for funded researchers. ${ }^{3,4}$ These 'facilitative' roles go beyond the traditional tasks of research funders and focus on actions that support implementation of research findings to improve health. ${ }^{5}$

In Australia, for example, the National Health and Medical Research Council (NHMRC) cites translation of research into population health and clinical policy and practice as one of three strategic priorities, and has instituted specific measures to support translation. These include partnership schemes that fund collaborative policy- and practice-relevant research, and Translating Research into Practice (TRIP) Fellowships, which support health professionals to translate evidence into healthcare and public health 
improvements. The NHMRC has also formally recognised several Advanced Health Research and Translation Centres - consortiums of universities, research institutes and hospitals collaborating to foster translation of medical research into improved patient care. Defining characteristics of these organisational collaborations include research excellence, programs and activities to accelerate research findings into healthcare, and health professional leaders who ensure that research knowledge is translated into policies and practices. ${ }^{6}$

Australian state and territory governments also play an important role in funding and supporting health and medical research aimed at improving health. This may take the form of capital funding for independent research institutes that focus on translating research into practical health improvements (e.g. the South Australian Health and Medical Research Institute), or more targeted funding for research projects with potential to be translated into policy or practice (e.g. the Research Translation Projects program of the Western Australian Department of Health). In the field of population health, VicHealth - the Victorian Health Promotion Foundation - supports a mix of research and evaluation projects (investigator led and strategic), fellowships and scholarships, and centres of excellence in research and practice. However, integrated jurisdictional approaches to funding population health research remain rare.

\section{Investment in integrated research}

Over the past decade, NSW (New South Wales) Health has systematically built and invested in an integrated population and health services research portfolio that includes different types of investment and policy focuses (Figure 1). These include: ${ }^{7}$

- Priority research centres funded through competitive tender to undertake a defined program of research in an area of priority for NSW Health. These centres include the BBV and STI Research, Intervention and Strategic Evaluation Program, which undertakes policy-relevant research to directly support NSW Health to reduce bloodborne viruses and sexually transmissible infections. NSW Health also provides financial and in-kind support to The Australian Prevention Partnership Centre, which is taking a systems approach to prevention of lifestyle-related chronic disease. Importantly, the Prevention Centre recognises policy makers as investigators, and is committed to partnerships between researchers and policy makers in knowledge production and translation $^{8}$

- Research infrastructure funding schemes such as the Population Health and Health Services Research Support (PHHSRS) Program, which gives

Figure 1. NSW Health population health and health services research portfolio

\begin{tabular}{|c|c|}
\hline Research assets & $\begin{array}{l}\text { - Centre for Health Record Linkage } \\
\text { - HealthStats NSW } \\
\text { - Secure Analytics for Population Health Research and Intelligence }\end{array}$ \\
\hline $\begin{array}{l}\text { Priority research } \\
\text { centres }\end{array}$ & $\begin{array}{l}\text { - Physical Activity, Nutrition and Obesity Research Group } \\
\text { - BBV and STI Research, Intervention and Strategic Evaluation Program }\end{array}$ \\
\hline $\begin{array}{l}\text { Competitive } \\
\text { funding schemes }\end{array}$ & $\begin{array}{l}\text { - Translational Research Grants Scheme } \\
\text { - Early-Mid Career Fellowships } \\
\text { - Prevention Research Support Program }\end{array}$ \\
\hline $\begin{array}{l}\text { Collaborative } \\
\text { research }\end{array}$ & $\begin{array}{l}\text { - NHMRC Partnership Centre: The Australian Prevention } \\
\text { Partnership Centre } \\
\text { - NHMRC Partnership Projects (e.g. The HIV prevention revolution: } \\
\text { measuring outcomes and maximising effectiveness) }\end{array}$ \\
\hline $\begin{array}{l}\text { Other research } \\
\text { and evaluation }\end{array}$ & $\begin{array}{l}\text { - Funding provided directly by policy areas for research projects } \\
\text { - Commissioned evaluations of policies and programs }\end{array}$ \\
\hline
\end{tabular}

$\mathrm{BBV}=$ bloodborne virus; HIV = human immunodeficiency virus; NHMRC = National Health and Medical Research Council; NSW = New South Wales; STI = sexually transmissible infection

a Funded by the NSW Health Office for Health and Medical Research; includes population health and health services research, among other research types.

b Formerly known as the Population Health and Health Services Research Support Program. 
infrastructure funding to high-achieving research organisations that have existing research programs in population health priority areas in NSW, and active relationships with NSW Health policy or practice partners

- Research translation support, including core funding for the Sax Institute to facilitate policy makers' access to high-quality, relevant research evidence (e.g. through commissioned rapid reviews of evidence), maintain and develop research assets, and enable collaborative research projects

- Research assets to enable researchers, planners and policy makers to conduct research to inform health policy decisions. These include the Centre for Health Record Linkage ( $\mathrm{CHeReL})$, which releases an estimated 500 million individual-level, linked and deidentified records for analysis each year.

Each of these investments has an explicit focus on translation. This ranges from a requirement that funding recipients engage policy stakeholders on research advisory committees or prepare evidence syntheses, through to an expectation of true coproduction of research, including joint identification of research questions, interpretation of results and dissemination of findings.

To date, there has been relatively little investigation of how different models used to fund research influence its impact on policy and practice. ${ }^{9}$ However, there are some indications that the approach of the NSW Health portfolio is strengthening generation and use of policy-relevant research. For example, a recent independent review of the PHHSRS Program highlighted case studies of local health service and policy translations facilitated through PHHSRS funding. A sample of these is available on the PHHSRS website (www.health.nsw.gov.au/research/ Pages/phhsrs.aspx). PHHSRS recipients report that this funding enabled strong relationships with policy partners and an 'embedded' approach to research, where researchers spent time within local service settings building relationships, and developing a deep understanding of system and service issues. ${ }^{10}$ In addition, a study of evidence reviews commissioned through the Sax Institute reported high levels of intended use of commissioned reviews, primarily to determine the details of a policy or program (77\%) but also to inform high-level planning or priority-setting processes (16\%). ${ }^{11}$

This strategic investment in policy-driven research in NSW reflects the Ministry's broader commitment to generating policy-relevant research, building collaborative programs and embedding quality research in the health system. ${ }^{12,13}$ This was enhanced in 2016 with the establishment of the Health Services Research Support Program (HSRSP) to support research undertaken in the health system and its translation. The HSRSP incorporates the Translational Research Grants Scheme (TRGS),

funding to improve the timeliness of ethics approvals and site-specific assessments, delivery of clinical trials for the medical use of cannabis, and work to commission a new population and secondary biobanking facility.

In 2016, the TRGS was launched to support practitioner-led research that can be directly translated into local practice and to reduce the time from evidence generation to adoption. The TRGS gives grants to NSW Local Health District and specialty health network staff for research and evaluation projects that translate into better patient outcomes, health service delivery, and population health and wellbeing.

It has been demonstrated that alignment with policy priorities, effective research partnerships and local champions are important factors for influencing the impact of government-funded research. ${ }^{14}$ Consistent with this evidence, proposals for funding under the TRGS required health service applicants to describe why their proposed research was a priority with reference to relevant state or local strategic plans, and identify and engage essential partners required for the successful conduct of the project and implementation of the findings. Importantly, applicants were also required to obtain certification from their chief executive confirming that practice change would be implemented locally, based on the results of the research. The requirement that chief executives commit to local practice change is, to our knowledge, unique to the TRGS.

Under Round 1 of the TRGS in 2016, 338 expressions of interest were received, with submissions from all Local Health Districts in NSW. The proposals related to several state-level health priority areas - including mental health (14.8\%), cardiovascular disease (11.8\%), diabetes (6.8\%), and drugs and alcohol (6.5\%) - or to specific issues that were demonstrated local priorities (40.8\%). Following peer review, 36 were invited to submit a full proposal and provided with tailored feedback, and 24 projects were funded. All unsuccessful expressionof-interest applicants were offered written tailored feedback and generic comments outlining the key factors of success. A review of Round 1 of the TRGS is being conducted to assess the processes for funding application appraisal and selection, and the impacts of TRGS-funded research in the short and medium terms.

\section{Conclusion}

By ensuring a long-term, sustained, strategic and integrated approach to priority-driven research generation, true coproduction of evidence and effective knowledge translation will continue to deliver results for NSW. The NSW Population Health Research Strategy 2017-2021, currently in development, will have a strong emphasis on fostering environments and actions to promote the use of research in policy and practice into the future. 


\section{Competing interests}

None declared

\section{Author contributions}

ST conceived and contributed to writing the paper. DC contributed to writing the paper. TL provided conceptual input into the development and writing of the paper.

\section{References}

1. Oliver K, Innvar S, Lorenc T, Woodman J, Thomas J. A systematic review of barriers to and facilitators of the use of evidence by policymakers. BMC Health Serv Res. 2014;14:2.

2. Moore G, Redman S, Haines M, Todd A. What works to increase the use of research in population health policy and programmes: a review. Evid Policy. 2011;7(3):277305.

3. Tetroe JM, Graham ID, Foy R, Robinson N, Eccles MP, Wensing $\mathrm{M}$, et al. Health research funding agencies' support and promotion of knowledge translation: an international study. Milbank Q. 2008;86:125-55.

4. Smits PA, Denis JL. How research funding agencies support science integration into policy and practice: an international overview. Implement Sci. 2014;9:28.

5. Brantnell A, Baraldi E, van Achterberg T, Winblad U. Research funders' roles and perceived responsibilities in relation to the implementation of clinical research results: a multiple case study of Swedish research funders. Implement Sci. 2015;10:100.

6. Lechler R, Walley T, Kelleher D, Schechter M. International panel review. Report to NHMRC from the International Panel - Advanced Health Research and Translation Centres. Canberra: National Health and Medical Research Council. 2015 [cited 2016 Dec 21] Available from: www.nhmrc.gov.au/_files_nhmrc/file/ research/ahrtc/ahrtcs_international_report_150327_0.pdf
7. NSW Department of Health. Promoting the generation and effective use of population health research in NSW: a strategy for NSW Health 2011-2015. Sydney: NSW Department of Health; 2010 [cited 2016 Dec 21]. Available from: www.health.nsw.gov.au/research/ Publications/pop-health-res-strat.pdf

8. Wilson A, Wutzke S, Overs M. The Australian Prevention Partnership Centre: systems thinking to prevent lifestyle-related chronic illness. Public Health Res Pract. 2014;25(1).

9. Redman S, Haynes A, Williamson A. Research impact: neither quick nor easy. BMC Med. 2015;13:265.

10. Campbell D, Stickney B, Milat A, Thackway S. Facilitating health research impact through infrastructure funding: the PHHSRS program. 2015 NHMRC Symposium on Research Translation; 2015 Oct 27-28; Sydney [cited 2016 Dec 21]. Available from: www.nhmrc.gov.au/_files_ nhmrc/file/media/events/2015/danielle_campbell.pdf

11. Moore GM, Redman S, Turner T, Haines M. Rapid reviews in health policy: a study of intended use in the New South Wales' Evidence Check programme. Evid Policy. 2016;12(4):505-19.

12. NSW Health. NSW state health plan: towards 2021. Sydney: NSW Ministry of Health; 2014 [cited 2016 Dec 21]. Available from: www.health.nsw.gov.au/ statehealthplan/Publications/NSW-state-health-plantowards-2021.pdf

13. NSW Health. NSW Government response to the NSW Health and Medical Research Strategic Review. Sydney: NSW Ministry of Health; 2012 [cited 2016 Dec 21]. Available from: www.health.nsw.gov.au/ohmr/Publications/ stratreview-gov-response.pdf

14. Milat AJ, Laws R, King L, Newson R, Rychetnik L, Rissel C, et al. Policy and practice impacts of applied research: a case study analysis of the New South Wales Health Promotion Demonstration Research Grants Scheme 2000-2006. Health Res Policy Syst. 2013;11:5.

\section{Copyright: (cc)()}

(C) 2017 Thackway et al. This article is licensed under the Creative Commons Attribution-NonCommercial-ShareAlike 4.0 International Licence, which allows others to redistribute, adapt and share this work non-commercially provided they attribute the work and any adapted version of it is distributed under the same Creative Commons licence terms. See: www.creativecommons.org/licenses/by-nc-sa/4.0/ 